\title{
Crowding-out effect and sorting in competitive labour markets with motivated workers
}

\section{Antoni Cunyat}

To cite this article: Antoni Cunyat (2019) Crowding-out effect and sorting in competitive labour markets with motivated workers, Applied Economics Letters, 26:4, 326-330, DOI: 10.1080/13504851.2018.1468550

To link to this article: https://doi.org/10.1080/13504851.2018.1468550

册 Published online: 26 Apr 2018.

Submit your article to this journal

凹 Article views: 56

View Crossmark data \lceil 


\section{Crowding-out effect and sorting in competitive labour markets with motivated workers}

\section{Antoni Cunyat}

Departament d'Anàlisi Econòmica, Universitat de València and ERI-CES, Valencia, Spain

ABSTRACT

This article makes a contribution to the economics literature by inducing proper self-selection into contracts based on workers' motivation. The novelty of our results is that it points out the alternative potential role of the crowding-out effect to separate workers based on their motivation.
KEYWORDS

Intrinsic motivation; adverse selection; competition

JEL CLASSIFICATION J33; D82; D86

\section{Introduction}

One of the most important tasks of a manager is to choose the right incentives for workers to provide effort. Linking pay to firm performance and fixed wages are two different incentive systems used among firms. Performance pay may provide incentives for workers to exert more effort, and with workers with different skills it may attract the best workers. On the other hand, performance pay may have a detrimental effect by crowding-out intrinsic motivation on motivated workers. ${ }^{1}$

The purpose of this article is to show how different incentive systems can arise in a labour market where motivated workers and selfish workers coexist. For this purpose, we modify Besley and Ghatak (2016)'s set-up by considering a competitive labour market where each firm employs one worker. There exist two types of workers: selfish and motivated workers. Selfish workers only respond to monetary incentives. Motivated workers not only respond to monetary incentives but their behaviour is also driven by intrinsic motivation. However, if a firm chooses an output-based reward system, their intrinsic motivation is undermined. Types and efforts are not observable for the firm and, therefore, there is adverse selection and moral hazard. Competition between firms is introduced using Rothschild and Stiglitz's notion of a competitive equilibrium under adverse selection.
The size of the crowding-out effect of performance pay on intrinsic motivation determines crucially the equilibrium. If the destruction of intrinsic motivation exceeds the costs of effort, there always exists a separating equilibrium in which firms offer two contracts. On the other hand, if the destruction of intrinsic motivation does not exceed the costs of effort, there always exists a pooling equilibrium in which the same contract is accepted by both types of workers. The novelty of our results is that it points out the alternative potential role of the crowding-out effect to separate workers based on their motivation.

This article makes a contribution to the economics literature by inducing proper self-selection into contracts based on workers' motivation. We take Besley and Ghatak (2016)'s noncompetitive labour market set-up as our starting point. These authors obtain a pooling equilibrium in which firms always offer the same contract to both types of workers and based on this outcome, they focus on the evolution of intrinsic motivation. In contrast, we consider a competitive labour market, and we obtain either a separating or a pooling equilibrium based on the size of the crowding-out effect. Related to our work is Kosfeld and Von Siemens' (2009, 2011), ${ }^{2}$ where a competitive labour market is considered in which workers differ in their intrinsic motivation for

CONTACT Antoni Cunyat Antonio.Cunat@uv.es E Departament d'Anàlisi Econòmica, Universitat de València and ERI-CES, Av/ dels Tarongers s/n. Campus dels Tarongers, Valencia 46022 Spain

${ }^{1}$ See work done by Deci (1971) on a seminal work on this matter.

${ }^{2}$ Other related research is done by Francois (2007) and Barigozzi and Burani (2016a, 2016b), among others.

(c) 2018 Informa UK Limited, trading as Taylor \& Francis Group 
cooperation and there is no crowding out. They show that there always exists a separating equilibrium in which workers sort into firms but, in their case, the existence of a separating equilibrium depends crucially on the existence of externalities between workers.

\section{The model}

Suppose an economy comprising a range of firms and workers where each firm can hire at most one worker. There is a continuum of workers of unit one and two types of workers $\rho \in\{m, s\}$ where $m$ stands for motivated and $s$ for selfish. Let $a$ be the fraction of motivated workers in the population which is assumed to be common knowledge across firms and workers. Effort is binary $e_{i} \in\{0,1\}$, costs of effort $c\left(e_{i}\right)$ are $c$ when $e_{i}=1$ and 0 when $e_{i}=0$.

Effort is not contractible whereas output is verifiable and, thus, contracts can depend on it. Output $(v)$ can take two values, $\bar{v}>0$ and $-v=0$. When a worker $i$ chooses effort $e_{i}=1$ output is $\bar{v}$, whereas when a worker $i$ chooses effort $e_{i}=0$ output is ${ }^{-} v=0$

Following Besley and Ghatak (2016), we assume that motivated workers enjoy a positive utility $\lambda>0$ from putting in effort. However, if motivated workers are paid for their effort they derive utility $-\phi$, where $\phi>0$. This assumption captures the crowding-out effect of monetary incentives on intrinsic motivation. ${ }^{3}$ We assume that $\lambda-\phi>c$, and, therefore, motivated workers always put in effort whether they are or not paid for their effort.

A contract offered to worker $i w_{i}=\left(\bar{b}_{i}(\bar{v}), \underline{b}_{i}(\underline{v}), f_{i}\right)$ has three elements, a transfer received by worker $i$ when output is high and low and a fixed transfer, respectively. Let $\beta=\bar{b}_{i}(\bar{v})-{ }^{-} b_{i}\left({ }^{-} v\right)$ be the bonus paid by the firm to worker $i$ in case of high output. For a bonus $\beta_{i}$, the meaning of $\phi\left(\beta_{i}\right)$ is the following: $\phi\left(\beta_{i}\right)=0$ if $\beta_{i}=0$ and $\phi\left(\beta_{i}\right)=\phi>0$ if $\beta_{i}>0$. We assume that there is a limited liability constraint. Workers are randomly matched with firms who post employment contracts and workers are assigned to firms in the following way. Given the contracts posted by firms, workers apply to a set of firms posting a specific contract. If they apply to more than one firm, they are chosen randomly among the applicants.

The utility ${ }^{4}$ of a worker $i$ who is of type $\rho$ is defined as follows:

$u_{i \rho}=\left\{\begin{array}{c}b_{i}\left[v\left(e_{i}\right)\right]+f_{i}-c\left(e_{i}\right) \text { if } \rho=s \\ \lambda\left(e_{i}\right)-\phi\left(\beta_{i}\right)+b_{i}\left[v\left(e_{i}\right)\right]+f_{i}-c\left(e_{i}\right) \text { if } \rho=m\end{array}\right.$

Selfish $i$ 's utility consists of two elements. The utility he enjoys from his wage $b_{i}\left[v\left(e_{i}\right)\right]+f_{i}$ and the costs from exerting effort $(c)$. In addition, motivated $i$ 's enjoy intrinsic satisfaction $\lambda>0$ from putting it effort. This intrinsic satisfaction is partially destroyed if the motivated worker is in an outputbased reward system $\left(\phi\left(\beta_{i}\right)\right)$.

Firms sell output at a price normalized to one. Given a contract $w_{i}=\left(\bar{b}_{i}(\bar{v}), \underline{b}_{i}(\underline{v}), f_{i}\right)$, let

$$
\pi\left(w_{i}, e_{i}\right)=v\left(e_{i}\right)-b_{i}\left[v\left(e_{i}\right)\right]-f_{i}
$$

be the firm's profit generated by a worker.

We assume that there is no rationing for workers and, therefore, all firms can employ a motivated or a selfish worker if they intend to.

We define a competitive equilibrium as follows. With regard to workers, we assume that equilibrium strategies form a perfect equilibrium given all possible sets of offered contracts. With regard to firms, the set of contracts $W$ offered by firms satisfy the following conditions as in the work done by Rothschild and Stiglitz (1976). First, no individual contract in $W$ earns negative profits. Second, there is no contract $\hat{w}$ outside of $W$ which would earn a strictly positive profit if an alternative contract outside $W$ is offered.

\section{The results}

We first describe workers' equilibrium behaviour within firms. Motivated workers always put in effort since the benefits of exerting effort are always greater than the costs. Therefore, $e_{m}^{*}\left(w_{m}\right)=1$ for any $w_{m}=$ $\left\{\left(\bar{b}_{m}(\bar{v}), \underline{b}_{m}(\underline{v}), f_{m}\right)\right\}$ as long as $\bar{b}_{m}(\bar{v}) \geq \underline{b}_{m}(\underline{v})$. On the other hand, selfish workers exert effort only if

\footnotetext{
${ }^{3}$ It is well established in labour economics and social psychology that extrinsic motivators such as monetary incentives can undermine intrinsic motivation. See work done by Frey and Jegen (2002) for a survey on motivation crowding theory.

${ }^{4}$ We assume that the worker's outside opportunity utility level is zero. In a competitive environment where workers are in the short side of the market, the outside option is irrelevant.
} 
the transfer in case of high output at least covers ${ }^{5}$ the costs of effort and the transfer in case of low output. Then, $e_{s}^{*}\left(w_{s}\right)=1$ for any $\bar{b}_{s}(\bar{v}) \geq{ }_{s}+c$, and $e_{s}^{*}\left(w_{s}\right)=$ 0 for any $\bar{b}_{s}(\bar{v})_{s}+c$.

We now show that transfers in case of high and low output should be specifically offered to each type of worker in any optimal contract. The bonus offered to a selfish worker must cover at least the costs of effort and the bonus offered to a motivated worker must be equal to zero.

Lemma 1 An optimal contract specifically targeted for selfish workers that induces high effort has a transfer in case of low output $\underline{b}_{s}=0$ and a transfer in case of high output $\bar{b}_{s} \geq c$, either under complete and incomplete information. ${ }^{6}$

Proof. From (1), selfish workers put in effort when $\bar{b}_{s}(\bar{v}) \geq \underline{b}_{s}(\underline{v})+c$. Therefore, the least expensive contract addressed to selfish workers inducing high effort is $\underline{b}_{s}=0$ and $\bar{b}_{s} \geq c$.

Lemma 2 An optimal contract specifically targeted for motivated workers that induces high effort has a transfer in case of low output $\underline{b}_{m}=0$ and a transfer in case of high output $\bar{b}_{m}=0$, either under complete and incomplete information.

Proof. Under complete information, from (1) a motivated worker always put in effort since $\lambda-\phi>c$. Therefore, the least expensive contract addressed to selfish workers inducing high effort is $\underline{b}_{m}=\bar{b}_{m}=0$. Under incomplete information, notice that any contract where $\underline{b}_{m}>0$ and/or $\bar{b}_{m}>0$ would only increase the probability of attracting selfish workers.

Since from Lemmas 1 and $2 \underline{b}_{s}=\underline{b}_{m}=0$, to simplify notation from now on let $\bar{b}_{m}=b_{m}$ and $\bar{b}_{s}=b_{s}$. Therefore, a contract offered by a firm can be expressed as $w=\left\{\left(b_{s}, f_{s}\right),\left(b_{m}, f_{m}\right)\right\}$.

\section{Incomplete information: separating equilibrium}

We first describe the Pareto-efficient separating contracts $^{7} w^{\prime}=\left\{f^{\prime}{ }_{s}, b_{s}{ }^{\prime}, f_{m}{ }^{\prime}, b_{m}{ }^{\prime}\right\}$. Selfish workers and motivated workers are offered, respectively, a contract that maximizes their utility and satisfies the self-selection, incentive-compatibility and limited-liability constraints.

The contract offered to a selfish worker $\left(f_{s}^{\prime}, b_{s}{ }^{\prime}\right)$ maximizes the utility of a selfish worker:

$$
u_{s}=f_{s}^{\prime}+b_{s}^{\prime}-c
$$

and satisfies the constraints:

$$
\begin{gathered}
\bar{v}-f_{s}{ }^{\prime}-b_{s}{ }^{\prime} \geq 0 \\
f_{s}{ }^{\prime}+b_{s}{ }^{\prime}-c \geq f_{m}{ }^{\prime} \\
\lambda-\phi\left(b_{s}{ }^{\prime}\right)+f_{s}{ }^{\prime}+b_{s}{ }^{\prime}-c \leq \lambda+f_{m}{ }^{\prime}-c \\
f_{s}{ }^{\prime}+b_{s}{ }^{\prime}-c \geq f_{s}{ }^{\prime} \\
f_{s}{ }^{\prime} \geq 0, f_{m}{ }^{\prime} \geq 0, b_{s}{ }^{\prime} \geq 0, b_{m}{ }^{\prime} \geq 0
\end{gathered}
$$

The zero-profit constraint (2) ensures that a firm makes no losses offering a contract $\left(f_{s}^{\prime}, b_{s}^{\prime}\right)$ to a selfish worker. (3) and (4) are the screening constraints which ensure that each type of worker prefers their respective contracts to the contracts for the other type. (5) is the incentive-compatibility constraint by which the selfish worker always exerts effort. Finally, (6) is the limited liability constraint.

On the other hand, the contract offered to a motivated worker $\left(f_{m}^{\prime}, b_{m}^{\prime}\right)$ maximizes the utility of a motivated worker:

$$
u_{m}=f_{m}^{\prime}-c
$$

and satisfies the constraints:

$$
\begin{gathered}
\bar{v}-f_{m}^{\prime} \geq 0 \\
\lambda+f_{m}^{\prime}-c \geq \lambda-\phi\left(b_{s}^{\prime}\right)+f_{s}^{\prime}+b_{s}^{\prime}-c \\
f_{m}^{\prime} \leq f_{s}^{\prime}+b_{s}^{\prime}-c \\
f_{s}^{\prime} \geq 0, f_{m}^{\prime} \geq 0, b_{s}^{\prime} \geq 0, b_{m}^{\prime} \geq 0
\end{gathered}
$$

By Lemma $1, b_{m}^{\prime}=0$ and, therefore the zero-profit constraint (7) reduces to $f_{m}^{\prime} \leq \bar{v}$. A motivated worker always exerts effort since $\lambda-\phi \geq c$ and there is no incentive-compatibility constraint. (8), (9) and (10) are the screening and limited liability constraints, respectively.

\footnotetext{
${ }^{5}$ In order to ensure a unique solution of the subgame where a worker chooses effort, we assume that workers choose to exert effort in case of indifference. ${ }^{6}$ With complete information, a firm knows whether the worker is selfish or motivated, whereas with incomplete information a firm is uncertain about the worker's type.

${ }^{7}$ With complete information, it is straightforward to check that firms obtain zero profit. Selfish workers are offered the contract $\left(f_{s}^{c}, b_{s}^{c}\right)$, where $f_{s}^{c}=\bar{v}-b_{s}^{c}$ and $b_{s}^{c} \in[c, \bar{v}]$ and motivated workers are offered the contract $\left(f_{m}^{c}, b_{m}^{c}\right)$, where $f_{m}^{c}=\bar{v}$ and $b_{m}^{c}=0$.
} 


\section{Proposition 3 (Separating equilibrium)}

If $\phi \geq c$, there is always a separating equilibrium characterized as follows:

(a) Selfish workers accept a contract from $\left(f^{\prime}, b_{s}^{\prime}\right)$, where $b_{s}^{\prime} \in[c, \bar{v}]$ and $f_{s}^{\prime}=\bar{v}-b_{s}^{\prime}$ and they exert effort.

(b) Motivated workers accept a contract from $\left(f_{m}^{\prime}, b_{m}^{\prime}\right)$, where $b_{m}^{\prime}=0$ and $f_{m}^{\prime}=\bar{v}-c$ and they exert effort.

(c) All firms make positive expected profits.

Proof. See Appendix

When $\phi \geq c$, a firm is always better off offering a different contract for each type of worker. If a selfish worker accepts the contract addressed to motivated workers, he does not exert effort and, therefore, he does not have costs of effort. As a consequence, motivated workers must receive a lower wage. The difference between the wage received by motivated and selfish workers is equal to the costs of effort, $c$, which is exactly the additional benefit a selfish worker would receive by accepting the motivated workers' contract. On the other hand, since the motivated worker receives a lower wage than the selfish one, it could happen that he prefers to accept the contract addressed to the selfish worker. Since this contract has a positive bonus, a motivated worker would have a disutility of $\phi$ by accepting it. However, when $\phi \geq c$, the motivated worker would obtain a lower utility by accepting the selfish workers' contract.

An important feature of our result is that opposed to Rothschild and Stiglitz (1976), a separating equilibrium exists even if the fraction of motivated workers becomes arbitrarily large.

\section{Incomplete information: pooling equilibrium}

A pooling equilibrium always exists when $\phi<c$.

\section{Proposition 4 (Pooling equilibrium)}

If $\phi<c$, there is always a pooling equilibrium characterized as follows:

(a) All firms offer the contract $(\widetilde{f}, \widetilde{b})$, where $\widetilde{b} \in$ $[c, \bar{v}]$ and $\widetilde{f}=\bar{v}-\widetilde{b}$.

(b) Selfish workers and motivated workers accept the contract $(\widetilde{f}, \widetilde{b})$ and exert effort. (c) All firms make zero expected profits

Proof. See Appendix.

The intuition is the following. If a firm wants to skim off motivated workers from selfish workers, it should offer the former ones lower wages. The difference between each type's contract has to be at least equal to the costs of effort, $c$. However, since $\phi<c$, a motivated worker is better off accepting the contract addressed to the selfish worker than the contract addressed to him.

\section{Disclosure statement}

No potential conflict of interest was reported by the author.

\section{Funding}

This research was funded by the Spanish Ministry of Economy, Project ECO2017-87245-R.

\section{References}

Barigozzi, F., and N. Burani. 2016a. "Competition and Screening with Motivated Health Professionals." Journal of Health Economics 50: 358-371. doi:10.1016/j. jhealeco.2016.06.003.

Barigozzi, F., and N. Burani. 2016b. "Screening Workers for Ability and Motivation." Oxford Economic Papers 68 (2): 627-650. doi:10.1093/oep/gpw005.

Besley, T., and M. Ghatak. 2016. Market Incentives and the Evolution of Intrinsic Motivation. Mimeo, UK.

Deci, E. L. 1971. "Effects of Externally Mediated Rewards on Intrinsic Motivation." Journal of Personality and Social Psychology 18: 105-115. doi:10.1037/h00 30644.

Francois, P. 2007. "Making a Difference." RAND Journal of Economics 38 (3): 714-732. doi:10.1111/j.07416261.2007.00108.x.

Frey, B., and R. Jegen. 2002. "Motivation Crowding Theory." Journal of Economic Surveys. 15 (5): 589-611.

Kosfeld, M., and F. Von Siemens. 2009. "Worker SelfSelection and the Profits from Cooperation." Journal of the European Economic Association 7 (2-3): 573-582. doi:10.1162/JEEA.2009.7.2-3.573.

Kosfeld, M., and F. Von Siemens. 2011. "Competition, Cooperation, and Corporate Culture." RAND Journal of Economics 42 (1): 23-43. doi:10.1111/j.17562171.2010.00124.x.

Rothschild, M., and J. Stiglitz. 1976. "Equilibrium in Competitive Insurance Markets: an Essay on The Economics Of Imperfect Information.” The Quarterly Journal Of Economics 90 (4): 629 649. doi:10.2307/1885326. 


\section{Appendix}

\section{Proof of Proposition 3}

We first show that in any separating equilibrium $\phi \geq c$. By Lemma $2, \quad b_{s}^{\prime} \geq 0$ and screening constraints hold if $f_{m}^{\prime}+c \leq f_{s}^{\prime}+b_{s}^{\prime} \leq f_{m}^{\prime}+\phi$. If $\phi<c$, these conditions do not hold.

Next, we show that in any separating equilibrium, selfish workers receive a contract from $\left(f^{\prime}{ }_{s}, b_{s}^{\prime}\right)$ and motivated workers receive a contract from $\left(f_{m}^{\prime}, b_{m}^{\prime}\right)$. Since the selfish workers have an incentive to accept a contract addressed to motivated workers (3) and (9) would be binding and

$$
f_{m}^{\prime}=f_{s}^{\prime}+b_{s}^{\prime}-c
$$

Using zero-profit condition for selfish workers (2), $f_{s}^{\prime}+b_{s}^{\prime} \leq$ $\bar{v}$. Replacing this expression in (4), we obtain $f_{m}^{\prime} \leq \bar{v}-c$. Therefore, zero-profit condition for motivated workers is not binding (7) and $f_{m}^{\prime}=\bar{v}-c$. On the contrary, zero-profit condition for selfish workers is binding and $f_{s}^{\prime}+b_{s}^{\prime}=\bar{v}$. Finally, using the incentive-compatibility constraint for selfish workers $b_{s}^{\prime} \geq c$. Then, $b_{s}^{\prime} \in[c, \bar{v}]$ and $f_{s}^{\prime}=\bar{v}-b_{s}^{\prime}$.

Finally, we prove existence by showing that there is no profitable market entry. Expected profits of a firm that offers the separating equilibrium contracts $w^{\prime}=\left\{f^{\prime}{ }_{s}, b_{s}^{\prime}, f_{m}^{\prime}, b_{m}^{\prime}\right\}$ are

$$
\begin{gathered}
\pi\left(w^{\prime}\right)=\alpha[\bar{v}-(\bar{v}-c)]+(1-\alpha)[\bar{v}-(\bar{v})] \\
\pi\left(w^{\prime}\right)=\alpha c
\end{gathered}
$$

It can be easily checked that there cannot be profitable market entry by firms that either attract only selfish workers or motivated workers.

There is no profitable market entry by firms offering the pooling contract $w^{*}=\left\{f^{*}, b^{*}\right\} \quad$ where $\quad b^{*}=0 \quad$ and $f^{*}=\bar{v}-c+\lambda$, where $\lambda \in(0, c)$. Profits would be

$$
\begin{gathered}
\pi\left(w^{*}\right)=\alpha[\bar{v}-(\bar{v}-c+\lambda)]+(1-\alpha)[-(\bar{v}-c+\lambda)], \\
\pi\left(w^{*}\right)=c-\lambda-(1-\alpha) \bar{v}
\end{gathered}
$$

and $\pi\left(w^{*}\right)<\pi\left(w^{\prime}\right)$. To check this, consider the function $g(\alpha)=\pi\left(w^{*}\right)-\pi\left(w^{\prime}\right)=-\lambda-(1-\alpha)(\bar{v}-c)$. Notice that $g(\alpha)<0$ for $\alpha \in[0,1]$ since $\bar{v}>c$.

Proof of Proposition 4

It can be easily checked that screening constraints do not hold when $\phi<c$ and there is no separating equilibrium.

Next, we characterize the pooling contract. First, notice that any pooling contract $\left(f^{*}, b^{*}\right)$ in which $f^{*}+b^{*}<\bar{v}$ has profitable market entry. Second, any pooling contract $\left(f^{\prime \prime}, b^{\prime \prime}\right)$ in which $b^{\prime \prime}<c$ is subject to profitable market entry. Therefore, the pooling contract with no profitable market entry is $(\widetilde{f}, \widetilde{b})$, where $\widetilde{b} \in[c, \bar{v}]$ and $\widetilde{f}=\bar{v}-\widetilde{b}$. 